\title{
Article Shape-Memory Properties of 3D Printed Cubes from Diverse
PLA Materials with Different Post-Treatments
}

\author{
Guido Ehrmann ${ }^{1}$ (D), Bennet Brockhagen ${ }^{2}$ and Andrea Ehrmann ${ }^{2, *(\mathbb{D}}$ \\ 1 Virtual Institute of Applied Research on Advanced Materials (VIARAM); guido.ehrmann@gmx.de \\ 2 Faculty of Engineering and Mathematics, Bielefeld University of Applied Sciences, 33619 Bielefeld, Germany; \\ bennet.brockhagen@fh-bielefeld.de \\ * Correspondence: andrea.ehrmann@fh-bielefeld.de
}

Citation: Ehrmann, G.; Brockhagen, B.; Ehrmann, A. Shape-Memory Properties of 3D Printed Cubes from Diverse PLA Materials with Different Post-Treatments. Technologies 2021, 9 , 71. https://doi.org/10.3390/ technologies 9040071

Academic Editors: Jeng-Ywan Jeng and Ajeet Kumar

Received: 29 August 2021

Accepted: 26 September 2021

Published: 29 September 2021

Publisher's Note: MDPI stays neutral with regard to jurisdictional claims in published maps and institutional affiliations.

Copyright: (C) 2021 by the authors. Licensee MDPI, Basel, Switzerland. This article is an open access article distributed under the terms and conditions of the Creative Commons Attribution (CC BY) license (https:// creativecommons.org/licenses/by/ $4.0 /)$.

\begin{abstract}
Poly(lactic acid) (PLA) belongs to the 3D printable materials which show shape-memory properties, i.e., which can recover their original shape after a deformation if they are heated above the glass transition temperature. This makes PLA quite an interesting material for diverse applications, such as bumpers, safety equipment for sports, etc. After investigating the influence of the infill design and degree, as well as the pressure orientation on the recovery properties of 3D printed PLA cubes in previous studies, here we report on differences between different PLA materials as well as on the impact of post-treatments after 3D printing by solvents or by heat. Our results show not only large differences between materials from different producers, but also a material-dependent impact of the post treatments. Generally, it is possible to tailor the mechanical and recovery properties of 3D printed PLA parts by choosing the proper material in combination with a chemical or temperature post-treatment.
\end{abstract}

Keywords: polylactic acid (PLA); shape-memory properties; fused deposition modeling (FDM); three-point bending test; post-treatment; solvent; heat

\section{Introduction}

In recent years, 3D printing has been developed further from an expensive technology for specialists, mostly used for rapid prototyping, to a broad range of different technologies capable of producing 3D objects from diverse materials, using equipment from low-cost desktop printers to highly sophisticated industrial-scale printers. While resin-based technologies are being developed further to print finer and finer structures from specialized materials [1,2], fused deposition modeling (FDM) technology is still most often used since it allows for the printing of diverse polymers without severe dangers to health and environment, in a relatively easy manner [3].

One of the most interesting materials for FDM printing is poly(lactic acid) (PLA). Due to its biodegradability and its cell-nontoxic properties, PLA is often used for biotechnological or biomedical applications [4-6]. PLA is easily printable at relatively low temperatures, when compared with other typical FDM printing filaments, and does not tend to warp, which is a well-known problem especially for acrylonitrile butadiene styrene (ABS) and some other printable polymers.

On the other hand, PLA has the problem that its mechanical properties are insufficient for several applications. This problem can on the one hand be solved by integrating fillers in the form of nanoparticles or nanofibers, or on the other hand by a heat post-treatment after 3D printing [7-9].

While PLA has relatively weak mechanical properties, it also offers a very special effect, i.e., shape-memory properties. This means that after a deformation of the material, it is able to recover its original shape to a certain extent under the influence of a sufficiently high temperature [10-12]. For PLA, this temperature is usually chosen between $60^{\circ} \mathrm{C}$ and $100^{\circ} \mathrm{C}$, i.e., above the glass transition temperature and well below the melting temperature [13-15]. 
While deformation at similar temperatures is relatively unproblematic, several possible applications of such shape-memory materials, e.g., in bumpers or safety equipment for sports, require that deformation at lower temperatures is possible without broken bonds, which could not be reconnected in pure PLA. This is why in previous studies we investigated the influence of the infill pattern [16] and the orientation of the applied quasistatic pressure [17] on the recovery properties of 3D printed PLA cubes and other shapes [18].

Here, based on these previous studies, we investigate the influence of the chosen PLA material as well as on different post-treatments by heat or solvents. While heat treatment of 3D printed PLA objects is often reported to improve their mechanical properties [19-21], solvent treatments are usually applied to reduce roughness or waviness of an FDM-printed object from PLA [22-24]. Here, the idea is to increase the elongation at the break, and thus reduce broken bonds during low-temperature deformation.

\section{Materials and Methods}

Cubes with dimensions of $(20 \mathrm{~mm})^{3}$ were printed with gyroid infill (without any walls, i.e., open to all six sides) and a filling degree of $25 \%$, corresponding to the optimum values found in the previous studies [16,17]. This infill pattern has the advantage of pores penetrating through the whole sample, enabling recovery with warm water which reaches the inner part of the cube fast. CAD images of the infill pattern can be found in $[16,17]$.

These specimens were 3D printed using an FDM printer I3 MK3 (Prusa Research A.S., Prague, Czech Republic) with a nozzle diameter of $0.4 \mathrm{~mm}$, corresponding to which layer thicknesses of $0.2 \mathrm{~mm}$ for the first layer and $0.15 \mathrm{~mm}$ for all other layers were chosen. The printing temperature was $215^{\circ} \mathrm{C}$ for the first layer and $210{ }^{\circ} \mathrm{C}$ for the subsequent layers, while the printing bed temperature was kept constant at $60{ }^{\circ} \mathrm{C}$.

The following PLA materials with diameter $1.75 \mathrm{~mm}$ were chosen for the tests:

- $\quad$ Silver-grey filament produced by Prusa Research A.S. (shore (78 \pm 2$) D)$

- Yellow filament produced by Filamentworld (Neu-Ulm, Germany) (shore (80 \pm 2$) D)$

- $\quad$ Red filament Fil-A-Gehr produced by Gehr (Mannheim, Germany) (shore (75 \pm 2$) D$ )

To avoid steadily repeating company names, the filaments will be named by their colors throughout the manuscript (grey, yellow and red, respectively). The filaments' shore hardness was measured using a durometer PCE-DD-D (PCE Instruments, Me schede, Germany), applied on 3D printed samples with 100\% linear infill and thickness $6 \mathrm{~mm}$.

In addition, pretests of the influence of different post-treatments were performed with several filaments (silver-grey PLA filament from Prusa Research A.S., PLA soft from Filamentworld as well as the thermoplastic polyurethane (TPU) "Ninjaflex" (from NinjaTek, Manheim, PA, USA). PLA soft and Ninjaflex were found to show no shapememory properties, thus the main tests were only performed with the different PLA materials listed above.

The following treatments of the filaments in the pretests and the 3D printed objects in the main test series were performed to test the influence on their mechanical properties:

- No treatment (original filament/raw specimen)

- Placing in water at room temperature for $4 \mathrm{~h}$

- Placing in ethanol at room temperature for $4 \mathrm{~h}$

- $\quad$ Placing in isopropyl alcohol (IPA) at room temperature for $4 \mathrm{~h}$

- Placing in acetone at room temperature for $4 \mathrm{~h}$ (Ninjaflex and PLA soft) or $1 \mathrm{~h}$ (PLA), respectively

- $\quad$ Placing in acetonitrile at room temperature for $4 \mathrm{~h}$ (Ninjaflex and PLA soft) or $1 \mathrm{~h}$ (PLA), respectively

- $\quad$ Placing in a microwave oven at $600 \mathrm{~W}$ for $3 \mathrm{~min}$

- Placing in an oven at $70{ }^{\circ} \mathrm{C}$ for $4 \mathrm{~h}$

Pretests were performed as tensile tests of the filaments in a universal testing machine (Kern \& Sohn GmbH, Balingen-Frommern, Germany) to find out which post-treatments may be suitable to improve the elongation at break and the tensile strength, and thus should 
be investigated in the main part of the study. The free clamping length was $50 \mathrm{~mm}$. Tests were performed in triplicates. Tensile tests here show negative values of the force, while subsequent pressing and recovery tests are given with opposite values, corresponding to the sign convention in our previous papers $[16,17]$. Since all filaments have diameters of $1.75 \mathrm{~mm}$, there is no necessity to normalize the measured forces according to the cross sections. Tensile tests were performed at $(60 \pm 5)$ min after taking the samples out of the solvents/microwave/oven.

Evaluation of the recovery properties was performed identically to the previous studies $[16,17]$, using a quasistatic load applied in the universal testing machine in which the doubled load pins on the lower side of a three-point bending test were exchanged by an even area. The rounded top load pin of the three-point bending test was pressed onto the top of the cubes along a diagonal; this orientation was found to be optimum for reaching high recovery in a previous study [17]. The maximum penetration of the load pin into the cube was $10 \mathrm{~mm}$, i.e., half the sample height. To protect the load cell, which can withstand a maximum force of $2 \mathrm{kN}$, the machine was programmed to stop at a force of $1.8-1.9 \mathrm{kN}$, depending on the slope of the force-deflection curve. The test speed was $6 \mathrm{~mm} / \mathrm{min}$. All cycles of deformation and recovery for $1 \mathrm{~min}$ in warm water of $(60 \pm 1)^{\circ} \mathrm{C}$ were repeated 10 times. These test conditions are identical to the previous studies.

To investigate possible chemical modifications of the material due to post-treatment, Fourier-transform infrared (FTIR) spectroscopy was performed by a spectroscope Excalibur 3100 (Varian Inc., Palo Alto, CA, USA) in attenuated total reflection mode (ATR-FTIR). Spectra from 4000 to $700 \mathrm{~cm}^{-1}$ were averaged over 32 scans each and corrected for atmospheric noise. Measurements were performed in triplicates to avoid improper signals on valley in the uneven surface/bottom of the brims (extended first layers increasing the adhesion of the 3D printed parts on the printing bed) which were used for the FTIR investigations.

Optical investigation of the samples was performed with a digital microscope Camcolms2 (Velleman, Gavere, Belgium).

\section{Results}

Firstly, Figure 1 shows FTIR spectra of the filaments under investigation. For PLA, here the yellow filament was chosen; all PLA materials with and without further treatment are discussed later.

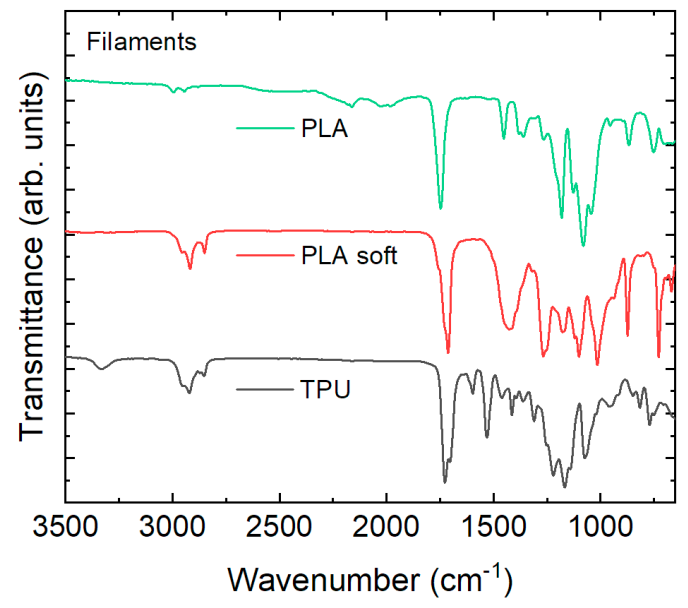

Figure 1. FTIR spectra of untreated filaments used in this study.

For TPU, there is NH stretching visible around $3300 \mathrm{~cm}^{-1}$, asymmetric and symmetric methylene stretching bands around $3000-2800 \mathrm{~cm}^{-1}$, a strong peak of hydrogen bonded urethane groups (amide I) at $1730-1700 \mathrm{~cm}^{-1}$, a smaller peak at $1597 \mathrm{~cm}^{-1}$ from $\mathrm{C}=\mathrm{C}$ skeletal stretching of the benzene ring and another large peak at $1529 \mathrm{~cm}^{-1}$, showing inplane $\mathrm{NH}$ deformation with $\mathrm{CO}$ and $\mathrm{CN}$ stretching (Amide II), as well as another prominent peak at $1072 \mathrm{~cm}^{-1}$ due to $\mathrm{C}-\mathrm{O}-\mathrm{C}$ stretching [25]. These peaks are typical for TPUs. 
PLA soft shows similar asymmetric and symmetric methylene stretching bands around $3000-2800 \mathrm{~cm}^{-1}$ and the hydrogen bonded urethane groups (amide I) at $1730-1700 \mathrm{~cm}^{-1}$, followed by some typical PLA peaks, but also a strong peak at $1269 \mathrm{~cm}^{-1}$, corresponding to $\mathrm{C}-\mathrm{O}$ in ester linkage, another sharp peak at $727 \mathrm{~cm}^{-1}$ showing methylene $\left(-\mathrm{CH}_{2}-\right)$ groups, and peaks between $900 \mathrm{~cm}^{-1}$ and $700 \mathrm{~cm}^{-1}$ according to benzene substitutes, all suggesting that PLA soft is a blend of PLA with poly(butylene adipate-co-terephthalate) (PBAT) [26-29].

Figure 2 depicts exemplary photographs of PLA (silver-grey), PLA soft (green) and TPU (yellow) with and without different treatments after the tensile tests. Most PLA and PLA soft filaments showed a special reaction towards tension which is visible in Figure 2a-they formed a constriction which became longer and longer, until it sometimes broke. This behavior was never recognized in TPU.

A special effect was visible after acetonitrile or acetone treatment of PLA (Figure 2b). In this case, the filament formed a white outer layer and became highly brittle. No such influence of these solvents was visible for PLA soft or TPU (Figure 2b). This finding suggests that acetone- or acetonitrile-treated PLA will show only small breaking forces in comparison with untreated or otherwise treated PLA filaments

It should be mentioned that only for acetone- or acetonitrile-treated PLA was there a difference between treated and untreated samples visible. Another small effect, a bleaching of red PLA by ethanol, will be shown later.

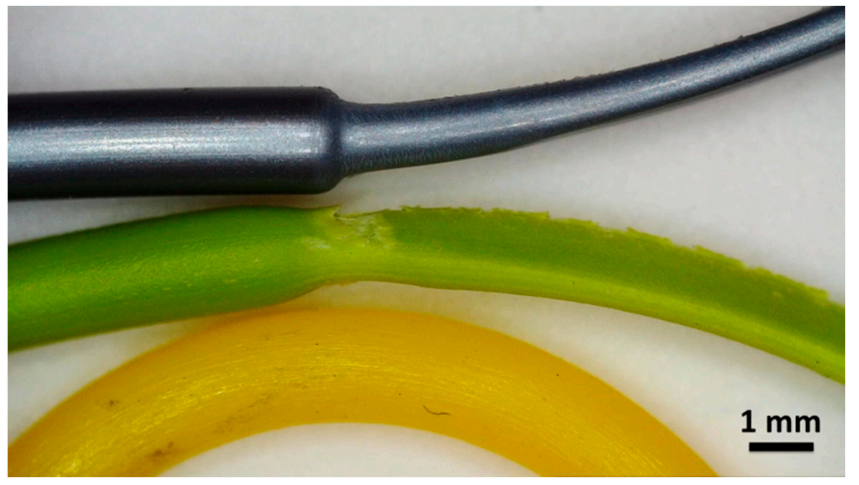

(a)

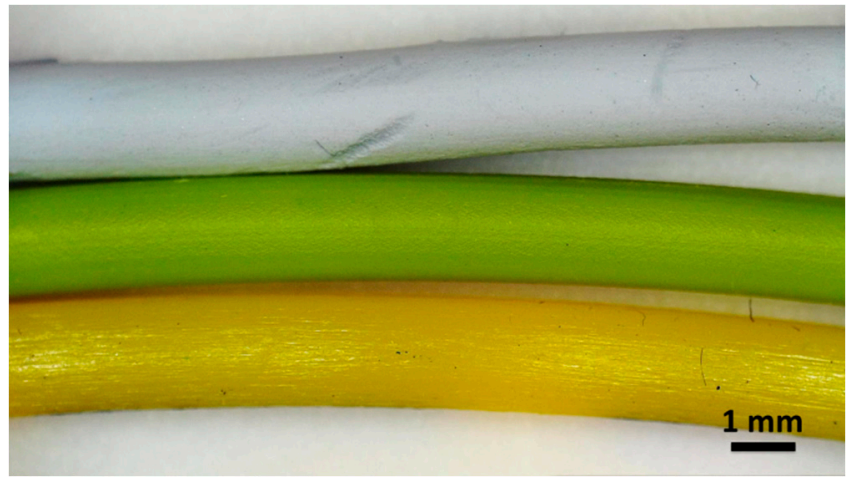

(b)

Figure 2. Filaments used in this study after tensile tests. (a) Untreated filaments; (b) filaments treated with acetonitrile.

The results of the pretests on different filaments are presented in Figures 3-5. According to the tests with the Ninjaflex TPU (Figure 3), most treatments make the material softer, i.e., the force for the maximum elongation reachable in the testing instrument is smaller. This is especially valid for acetone, while water and microwave heating cause the smallest changes.

While Ninjaflex never broke within the possible elongation of nearly 100\%, PLA soft in its original state broke at approximately $5 \mathrm{~mm}$ elongation, i.e., $10 \%$ (Figure $4 \mathrm{a}$ ). Interestingly, the different treatments showed quite different effects. Water and microwave heating led to a significant increase in the maximum force as well as in the elongation at break (Figure 4b,c). A similar, but smaller effect is visible for IPA (Figure 4d). 


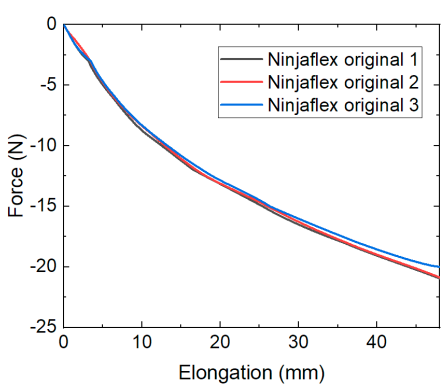

(a)

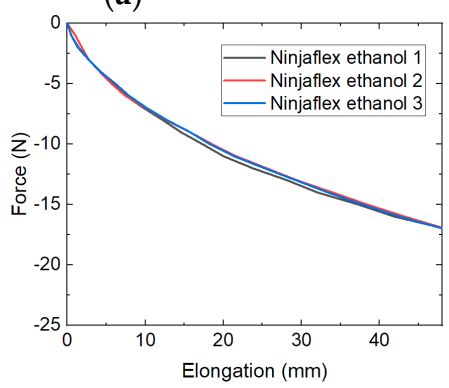

(e)

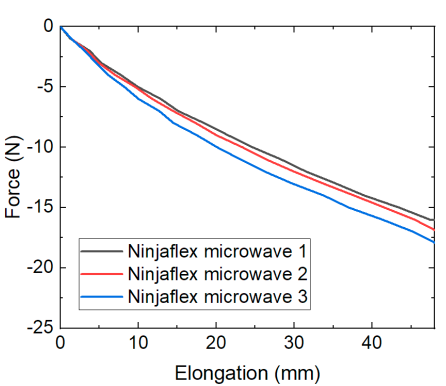

(b)

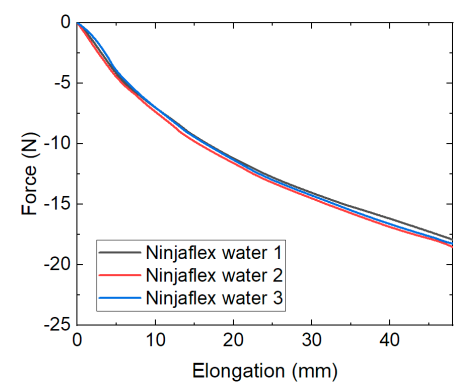

(c)

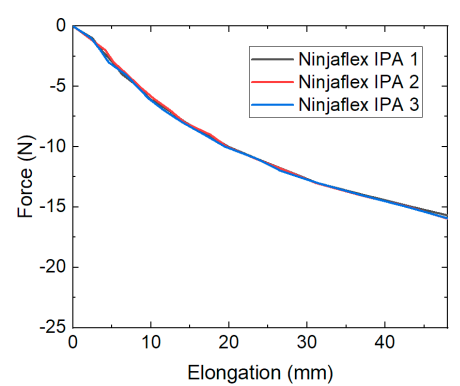

(d)

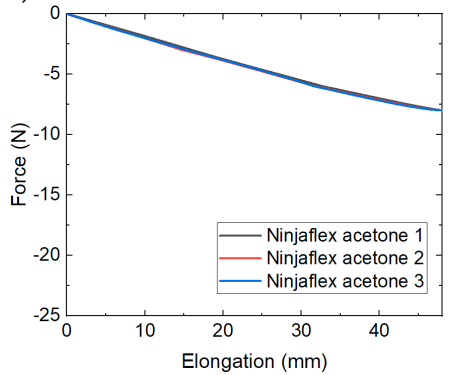

(f)

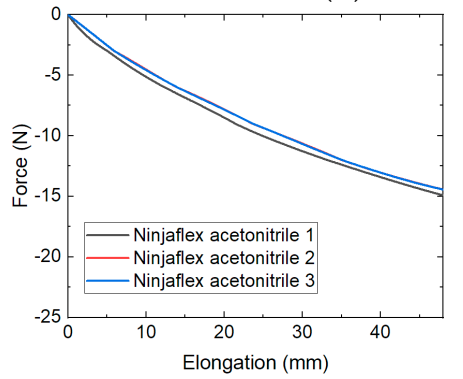

(g)

Figure 3. Tensile pretests on Ninjaflex TPU filaments after different treatments: (a) original state (no treatment); treatment (b) by microwave; (c) in water; (d) in fluid IPA; (e) in fluid ethanol; (f) in fluid acetone; (g) in fluid acetonitrile.

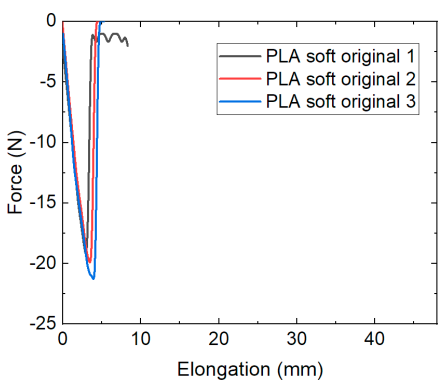

(a)

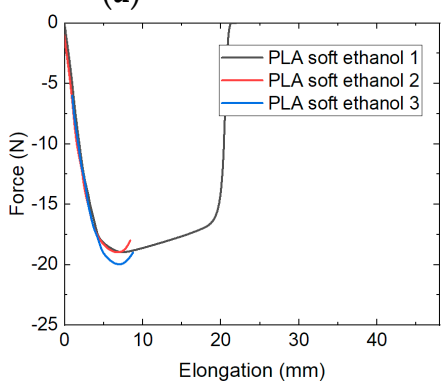

(e)

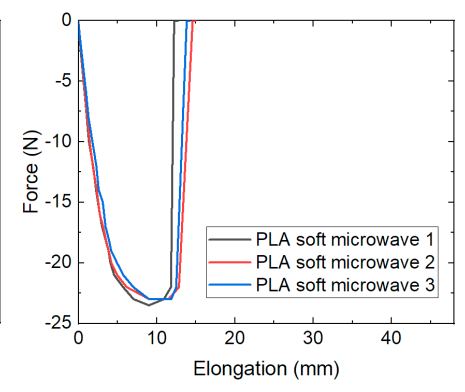

(b)

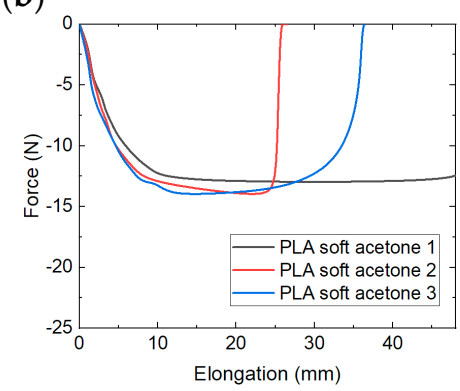

(f)

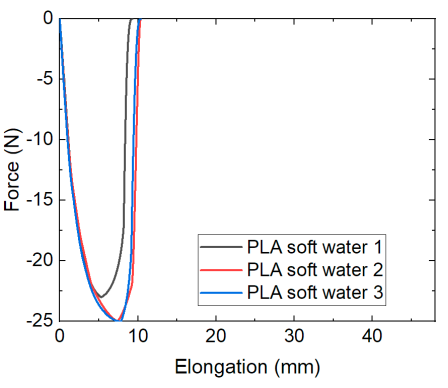

(c)

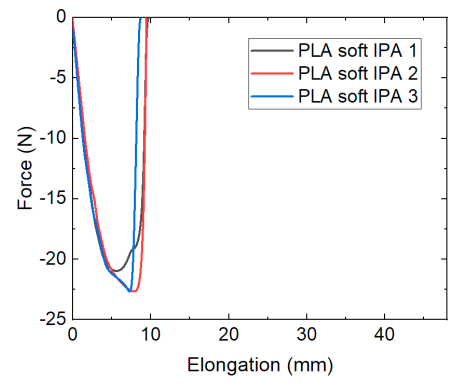

(d)

Figure 4. Tensile pretests on PLA soft filaments after different treatments: (a) original state (no treatment); treatment (b) by microwave; (c) in water; (d) in fluid IPA; (e) in fluid ethanol; (f) in fluid acetone; (g) in fluid acetonitrile.

Ethanol, acetone and acetonitrile, on the other hand, reduced the maximum force, but significantly increased the elongation at break (Figure $4 \mathrm{e}-\mathrm{g}$ ). This suggests that some of the treatments investigated here may be suitable to increase the elongation at break, thus resulting in lower amounts of broken bounds during deformation, while simultaneously not reducing the maximum force with which a sample withstands deformation.

It must be mentioned, however, that PLA soft was found to show no shape-memory properties, so this material was not investigated further in the main test series. 
Thus, pure PLA (grey) filament was also investigated by tensile tests (Figure 5). Firstly, when comparing the original filament (Figure 5a) with the water treated one (Figure 5c) not much difference is visible. The maximum force of the water-treated filament is again slightly increased, showing that the tests performed in this study-using warm water to recover the specimens after low-temperature deformation-do not negatively influence the mechanical properties of the specimens and could thus be used in practical applications of such shape-memory materials.

Unexpectedly, IPA and ethanol do not show a large impact, while the microwave treatment significantly increases the elongation at break. Here, both acetone and acetonitrile treatments-performed for only $1 \mathrm{~h}$ due to the visible modifications of the filaments which became white and started breaking - were clearly unsuitable for reaching a positive impact on the PLA filament.

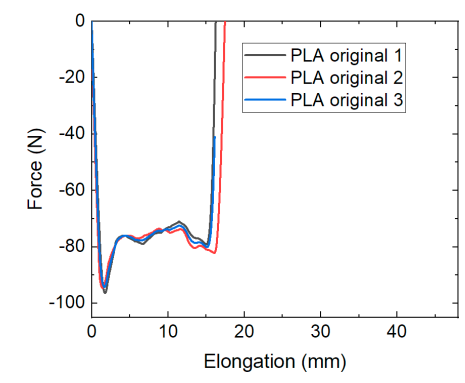

(a)

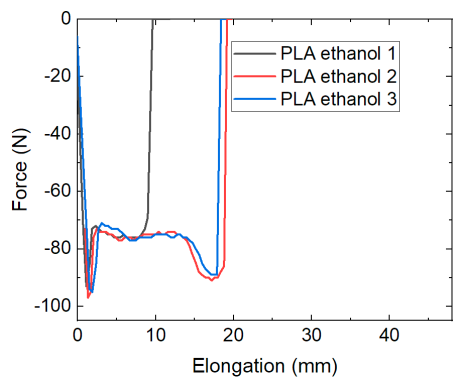

(e)

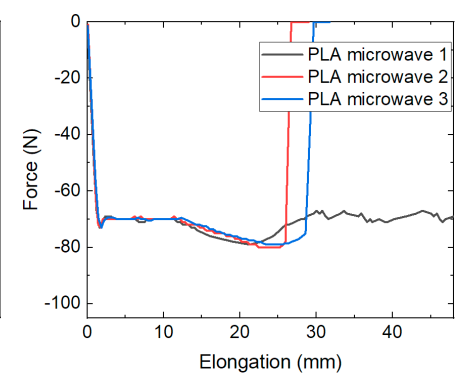

(b)

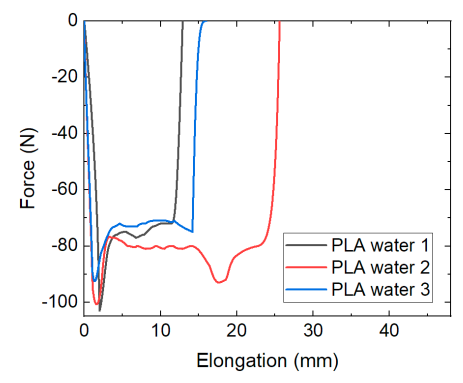

(c)

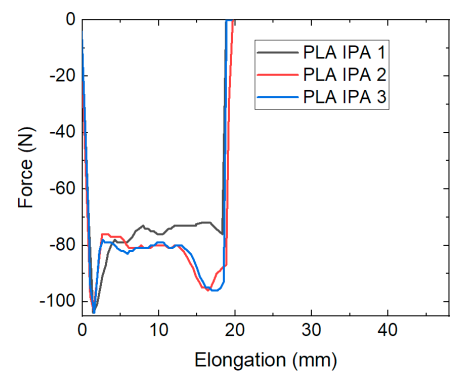

(d)

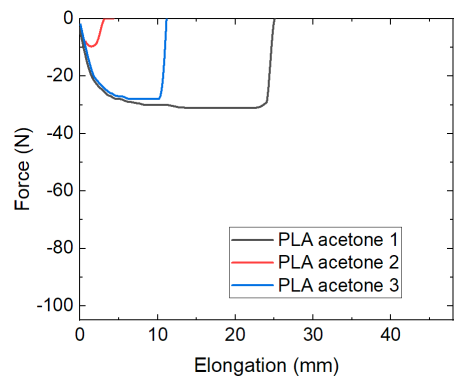

(f)

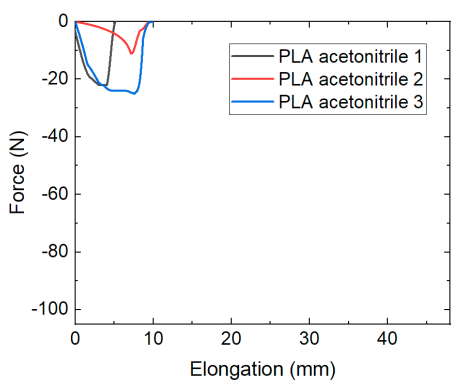

(g)

Figure 5. Tensile pretests on PLA (grey) filaments after different treatments: (a) original state (no treatment); treatment (b) by microwave; (c) in water; (d) in fluid IPA; (e) in fluid ethanol; (f) in fluid acetone; (g) in fluid acetonitrile. The $y$-axis differs from Figures 1 and 2.

According to these pretests and the clearly negative influence of acetone and acetonitrile on PLA, these solvents were excluded from the main test series. On the other hand, the positive influence of the microwave treatment suggested adding a heat treatment in the main test series. Therefore, Figures $6-8$ show the aforementioned recovery tests for the three different PLA materials under investigation after post-treatments with water, microwave, heating, IPA and ethanol in comparison with the raw (as-printed) specimens.

For the yellow PLA (Figure 6), comparing the first test cycles (red curves) shows that the maximum impact force is reached for the raw (as-printed) specimen at approximately $5 \mathrm{~mm}$ (Figure 6a) and at a similar value after heat treatment (Figure 6c). For ethanol, the material becomes significantly softer, allowing an impact of the maximum test value of $10 \mathrm{~mm}$ without reaching the force limit.

Another point which has to be taken into account is the residual deformation which is given by the highest impact with a force of $0 \mathrm{~N}$. After 10 test and recovery cycles of the raw material, this value is $5.5 \mathrm{~mm}$, similar to most other values. It becomes significantly higher for the heat treatment (Figure 6c), showing that this treatment impedes recovery of the original shape. 


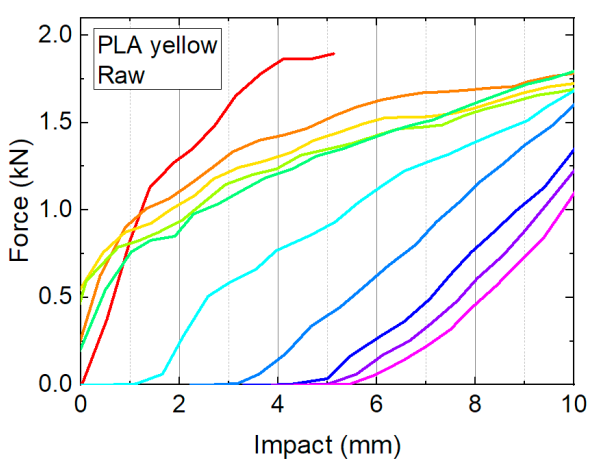

(a)

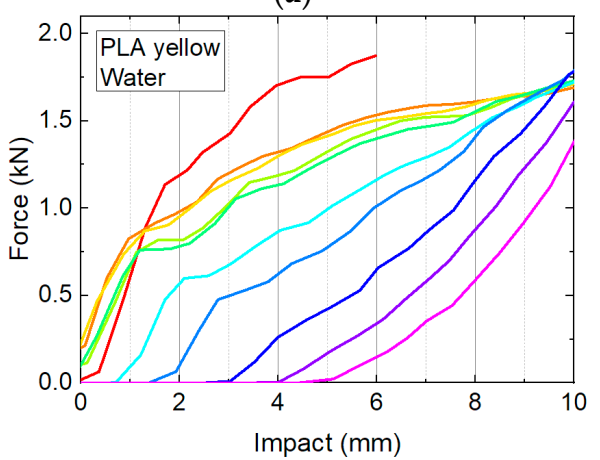

(d)

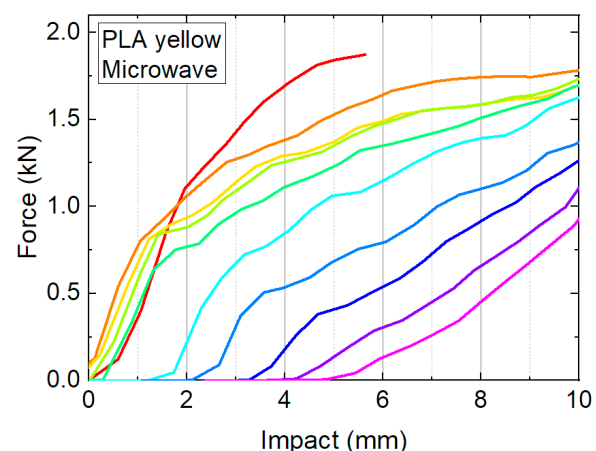

(b)

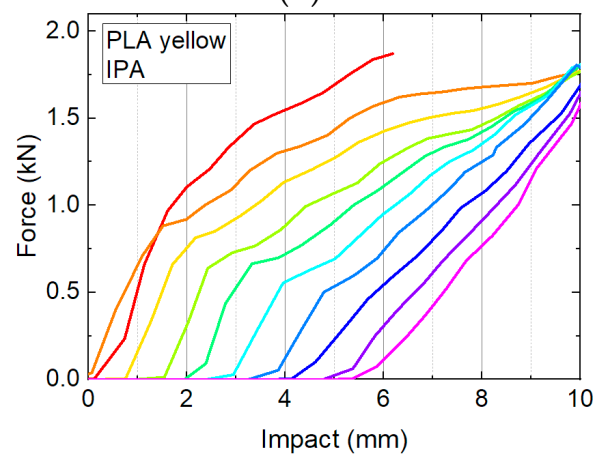

(e)

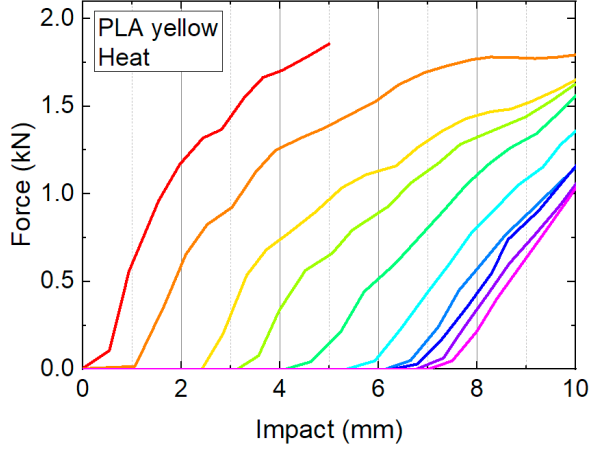

(c)

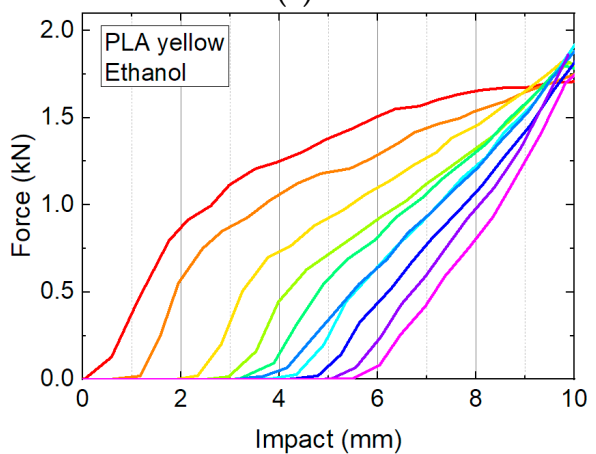

(f)

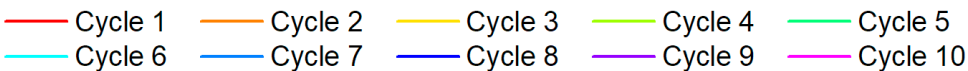

Figure 6. Quasistatic load tests in original state and after several test and recovery processes of different samples of PLA yellow: (a) raw (no treatment); treatment (b) by microwave; (c) by heat; (d) in water; (e) in fluid IPA; (f) in fluid ethanol.

A third interesting parameter is the maximum force reached for an impact of $10 \mathrm{~mm}$ after 10 test and recovery cycles. Unexpectedly, this value is highest for the ethanol treated sample, while ethanol was originally assumed to make the material softer.

It must be mentioned that for the three fluid treatments (Figure $6 \mathrm{~d}-\mathrm{f}$ ), there is an effect visible which is called work hardening (or strain hardening), stemming from movement of dislocations inside the material, which was not recognized in the previous studies $[16,17]$ nor in the test of the original material (Figure 6a).

Next, Figure 7 shows the investigations performed on the grey PLA used in the previous studies $[16,17]$.

Similar to PLA yellow, the material becomes slightly softer during the first test cycle after a microwave treatment (Figure 7b) and significantly softer after an ethanol treatment (Figure 7f). The residual deformation is here by far lowest for the raw material (Figure 7a). After 10 test and recovery cycles, the lowest force at an impact of $10 \mathrm{~mm}$ is found after the heat treatment (Figure 7c) and the highest force after the water treatment (Figure 7d).

Comparing these results with the previous ones shows that on the one hand that the behavior of the raw specimens differs strongly, in particular the residual impact is much smaller for the grey PLA (Figure 7a) than for the yellow one (Figure 6a). Repeating these tests with identical specimens revealed the same result. On the other hand, no work hardening occurred for the ethanol treated PLA grey sample.

Figure 8 depicts the results of testing the PLA red. The first cycle is again stopped due to the force limit at approximately $5 \mathrm{~mm}$ for the raw material and the IPA-treated specimen, while microwave, heat and water treatment make the specimens slightly harder, and ethanol extends the reached impact during the first cycle. Here, opposite to both other materials, even for the ethanol treatment no impact of $10 \mathrm{~mm}$ is reached during the first cycle. 


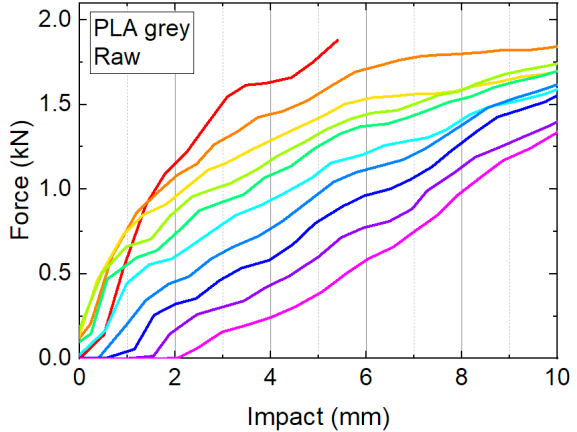

(a)

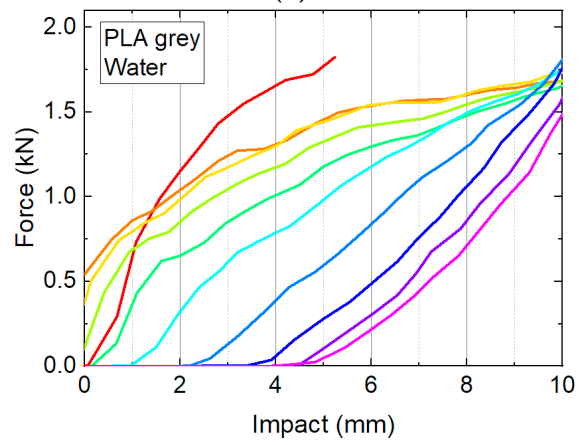

(d)

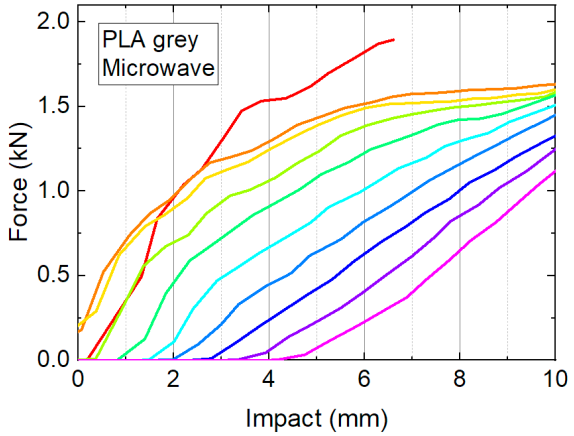

(b)

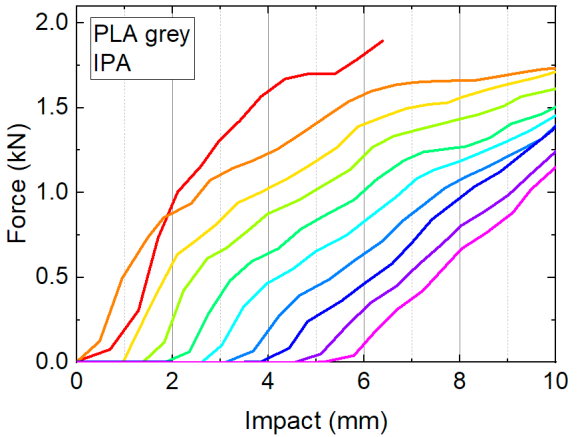

(e)

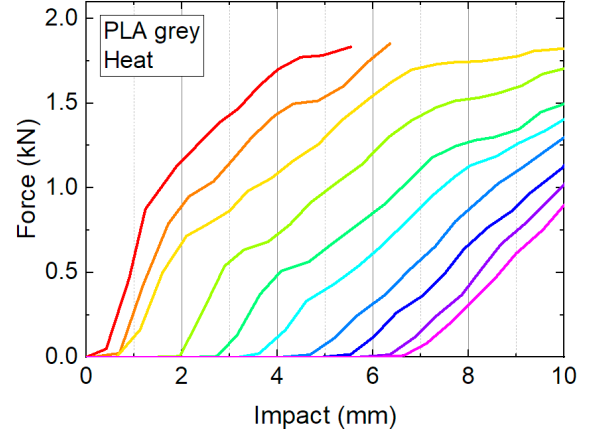

(c)

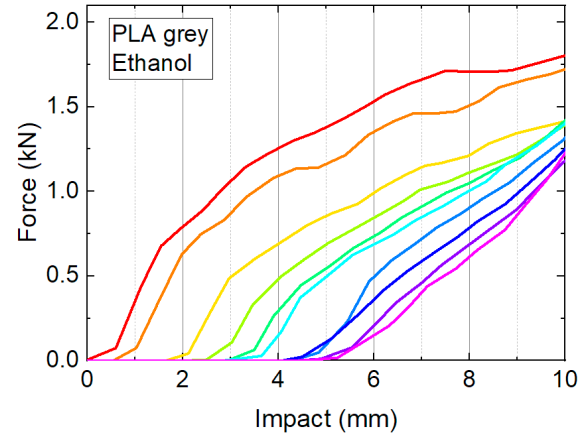

(f)

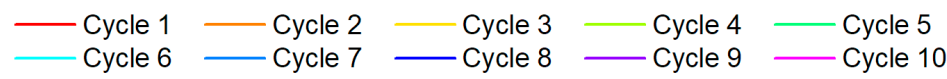

Figure 7. Quasistatic load tests in original state and after several test and recovery processes of different samples of PLA grey: (a) raw (no treatment); treatment (b) by microwave; (c) by heat; (d) in water; (e) in fluid IPA; (f) in fluid ethanol.

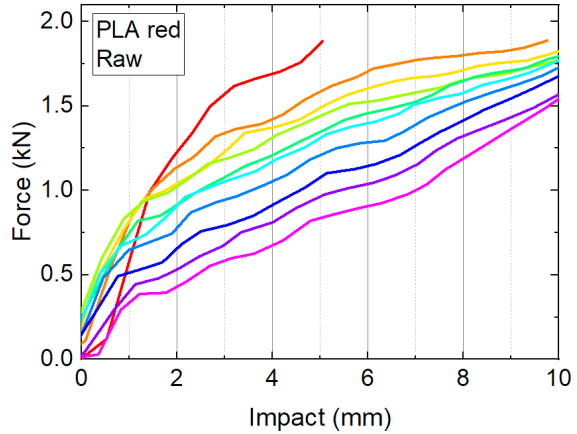

(a)

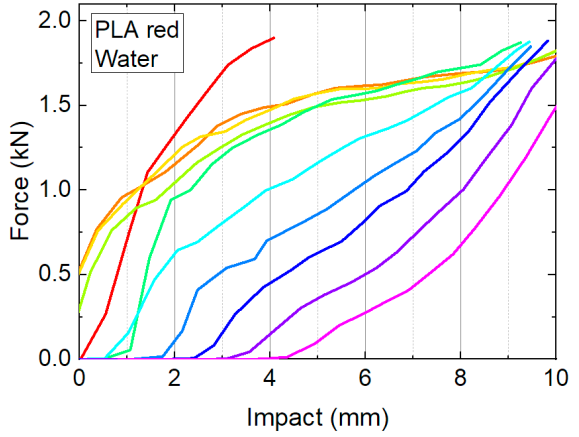

(d)

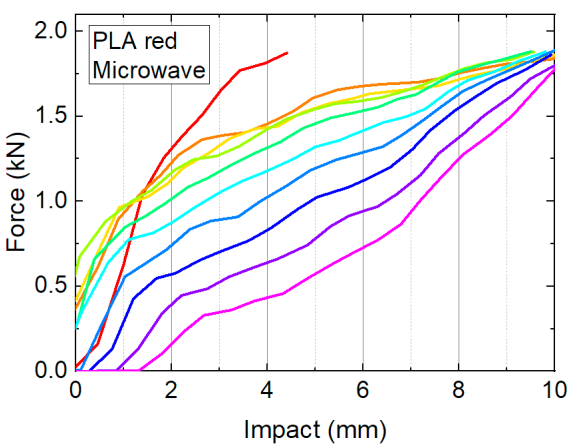

(b)

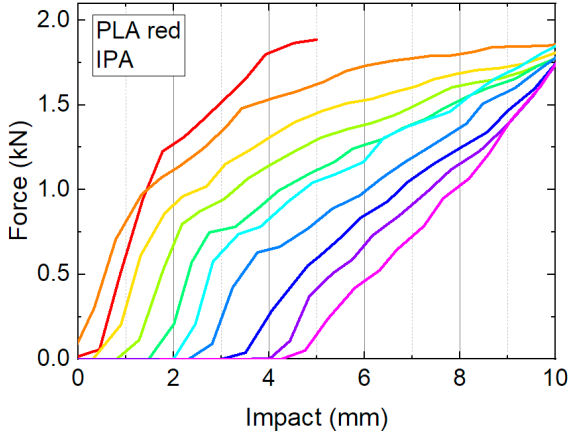

(e)

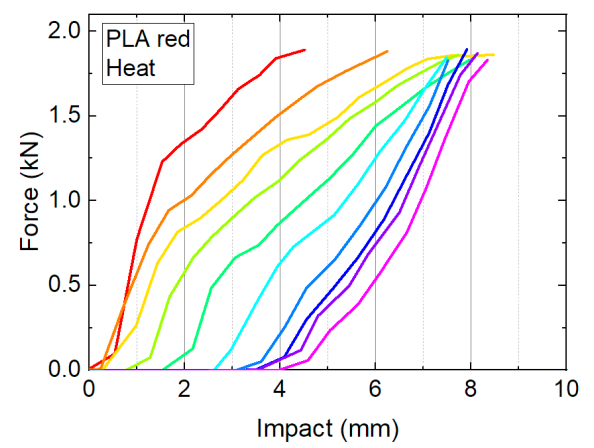

(c)

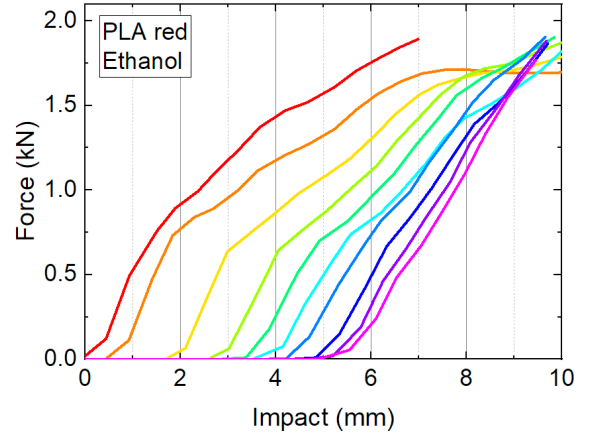

(f)

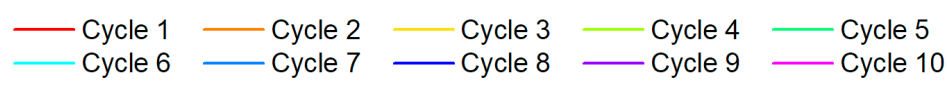

Figure 8. Quasistatic load tests in original state and after several test and recovery processes of different samples of PLA red: (a) raw (no treatment); treatment (b) by microwave; (c) by heat; (d) in water; (e) in fluid IPA; (f) in fluid ethanol. 
The residual deformation of the raw material is significantly lower than for both other materials (Figure 8a), while the values become similar to the other materials for the different treatments. For ethanol, again a strong work hardening can be recognized, reaching the maximum force even below an impact of $10 \mathrm{~mm}$ (Figure 8f). Unexpectedly, the heat treatment (Figure $8 \mathrm{c}$ ) leads to an even stronger effect, resulting in none of the test cycles reaching the maximum impact of $10 \mathrm{~mm}$ without exceeding the maximum possible force.

A few exemplary images of samples after 10 test cycles are depicted in Figure 9. It must be mentioned that due to the diagonal orientation of the pressing orientation, the depth of the residual deformation can be more easily quantitatively evaluated from Figures 6-8; however, these images should give a qualitative impression of the deformation in all orientations after the tests.

For the yellow PLA samples, a certain difference between the water-treated specimen (Figure 9a) and the heat-treated one (Figure 9b) is visible, with the latter showing a slightly stronger residual deformation. However, this difference is very small, as it is also visible in Figure 6 where the residual deformations after 10 test cycles were similar for all treatments.

The difference between both grey PLA specimens-untreated (Figure 9c) and heattreated (Figure 9d) - is more strongly visible, as it can also be seen in Figure 7, where the untreated grey PLA showed the smallest residual deformation and the heat-treated specimen belonged to those with a large residual deformation.

Finally, the red untreated PLA shows, on the one hand, the significantly smallest residual deformation (Figure 9e), when compared with other types of PLA, while the red PLA after ethanol treatment stays more strongly deformed, and shows, as the only sample in this test series, a color change (Figure 9f). Whether the latter was related to the different PLA or different color was not investigated further due to the low performance of this sample.

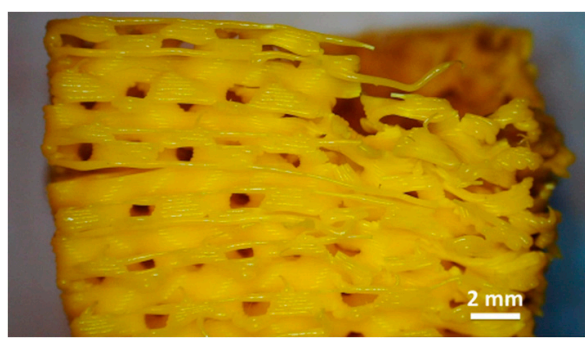

(a)

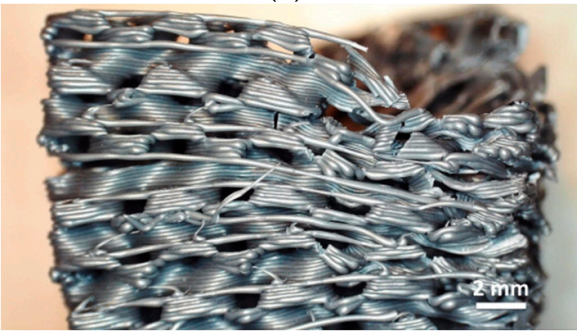

(d)

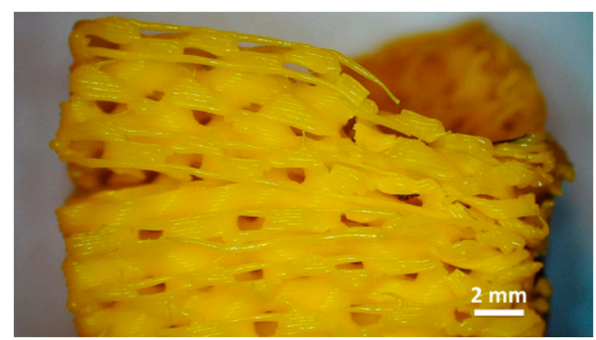

(b)

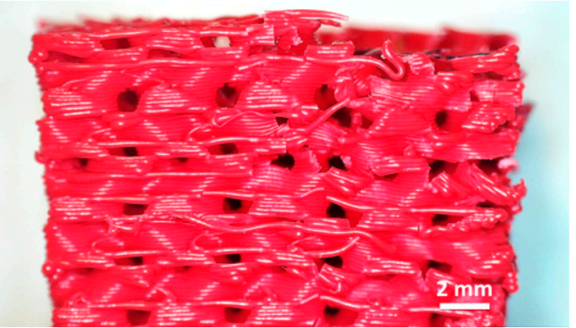

(e)

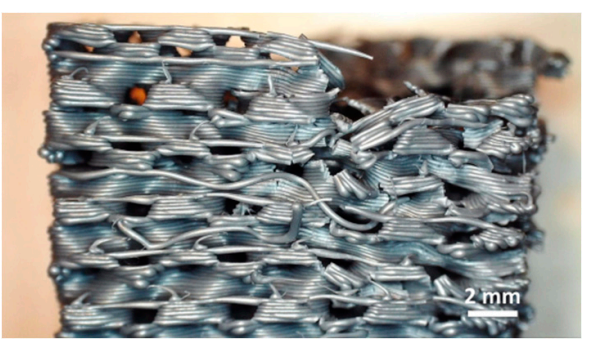

(c)

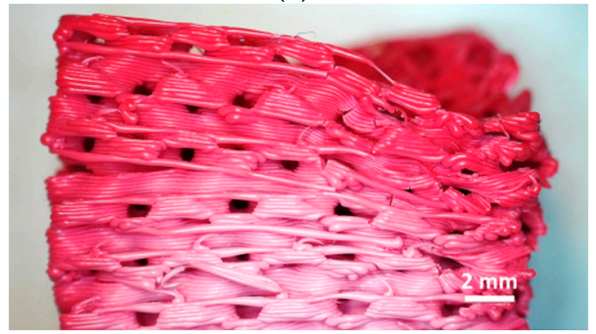

(f)

Figure 9. Microscopic images of exemplary PLA samples after 10 pressing and recovery cycles: (a) PLA yellow with water treatment; (b) PLA yellow with heat treatment; (c) PLA grey without treatment; (d) PLA grey with heat treatment; (e) PLA red without treatment; (f) PLA red with ethanol treatment. Dark marks on top of the samples mark the pressing lines and are not related to any treatment or mechanical deformation.

Another point which is visible here is the importance of the free spaces between the infill walls of the gyroid structure, which enables these large deformations of half of the sample height during the tests. While previous tests showed a slightly lower performance for lower infill ratios of $15 \%$ or $20 \%$, it can be expected that much higher infill ratios will not lead to stronger samples, but to larger deformations as the material no longer has space 
enough to spread into previous pores with small displacements, but has to make large shifts as soon as it cannot withstand the applied force anymore.

Comparing the behavior of these arbitrarily chosen PLA materials shows how strongly the materials in their raw state, after 3D printing and after the different post-treatments, differ. This underlines on the one hand that for a certain application, it is not possible to use any PLA as the printing material, but several PLA materials have to be characterized well in terms of the specific requirements, so that the best one can be chosen. On the other hand, the strongly different influences of diverse heat and solvent treatments must be taken into account. It must be emphasized that such strongly different reactions of nominally identical materials to the impact of identical post-treatments can cause large, unexpected deviations from the expected result. This fact may be part of the problem that, in spite of the large number of studies working on optimizing 3D printing parameters for PLA and other materials, the results are often not reproducible or even are contradictory. Apparently, it is necessary to define better methods to carefully characterize FDM printing filaments than by just naming the main polymer.

One approach to perform a better material characterization can be given by FTIR spectroscopy. Figure 10 thus shows FTIR measurements performed on the different 3D printed PLA materials before and after post-treatments. The numbered marks in the spectra are at identical positions in all three graphs to enable easier comparison.

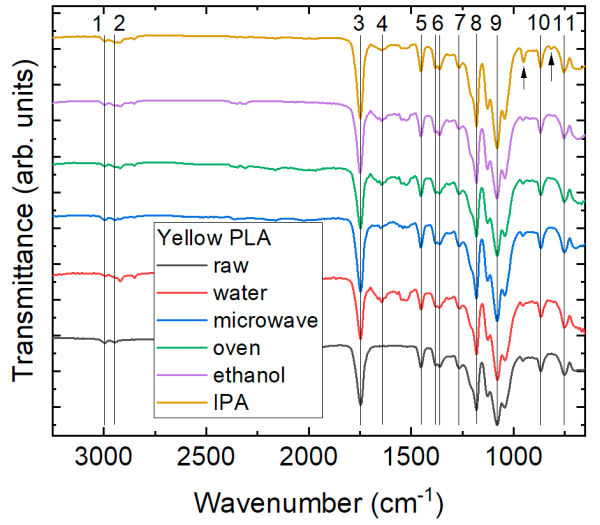

(a)

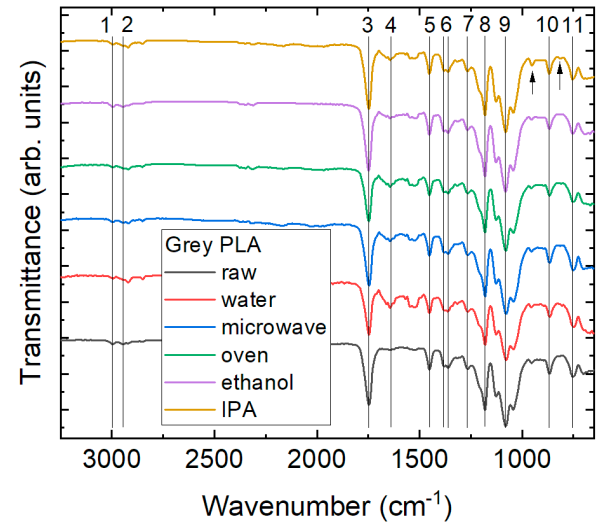

(b)

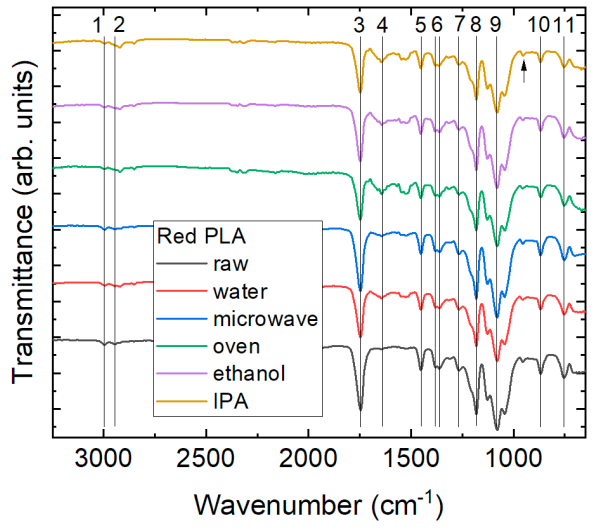

(c)

Figure 10. FTIR transmittance measurements of post-treated and untreated samples: (a) PLA yellow; (b) PLA grey; (c) PLA red.

Firstly, the spectra show typical PLA peaks:

1. $2998 \mathrm{~cm}^{-1}-\mathrm{CH}$ stretching mode (asymmetric) $[30,31]$

2. $2946 \mathrm{~cm}^{-1} \_\mathrm{CH}$ stretching modes (symmetric) $[30,31]$

3. $1747 \mathrm{~cm}^{-1}$ - stretching vibrations of amorphous carbonyl groups $-\mathrm{C}=\mathrm{O}$, characteristic for aliphatic polyesters [30,32-34]

4. $\quad 1639 \mathrm{~cm}^{-1}-(\mathrm{C}=\mathrm{C})$ stretching vibrations due to thermal decomposition $[32,33]$

5. $\quad 1451 \mathrm{~cm}^{-1}-\mathrm{CH}_{3}$ (methyl) asymmetric deformations $[31,34,35]$

6. $1385 \mathrm{~cm}^{-1}+1359 \mathrm{~cm}^{-1}-\mathrm{CH}-$ symmetric and asymmetric bending [31]

7. $1268 \mathrm{~cm}^{-1}-\mathrm{C}=\mathrm{O}$ bending [32]

8. $1182 \mathrm{~cm}^{-1} \_\mathrm{C}-\mathrm{O}-\mathrm{C}$ symmetric stretching (ester) $[30,31,34]$

9. $1082 \mathrm{~cm}^{-1} \_\mathrm{C}-\mathrm{O}-$ asymmetric stretching [30-32]

10. $868 \mathrm{~cm}^{-1}-\mathrm{C}-\mathrm{C}$ backbone stretching [30,31,34], typical for an amorphous phase

11. $754 \mathrm{~cm}^{-1}$-skeletal vibration of the methylene groups $-\mathrm{CH}_{2}-$, typical for the amorphous phase [36]

The arrows marked for the IPA treated specimens indicate additional peaks:

- $951 \mathrm{~cm}^{-1}$-helical backbone vibrations with the $\mathrm{CH}_{3}$ rocking modes or vinyl groups, allowing for characterization of amorphous PLA [32,33,36] 
- $815 \mathrm{~cm}^{-1}$-deforming vibrations of the $\mathrm{CH}$ and $\mathrm{CH}_{2}$ in ketones $\left(\mathrm{RCOCH}=\mathrm{CH}_{2}\right)$ and / or vinyl ethers $\left(\mathrm{ROCH}=\mathrm{CH}_{2}\right)$ [33]

Besides the peaks marked with arrows, the residual peaks remain quite similar and do not suggest quantitative differences between the different raw materials or the treatments. Generally, it can be stated that no hints for crystalline PLA can be found which should be visible, e.g., by a peak at $921 \mathrm{~cm}^{-1}[32,36]$, while peaks typical for amorphous PLA can be found at $868 \mathrm{~cm}^{-1}, 754 \mathrm{~cm}^{-1}$ and also in form of the additional peak at $951 \mathrm{~cm}^{-1}$, mostly found after IPA treatment. Thus, no significant crystallization can be expected to occur.

On the other hand, typical degradation peaks [35], such as a broad band with a maximum at $3500 \mathrm{~cm}^{-1}$ that corresponds to degradation products such as hydroperoxides or alcohols (not shown here), a narrow band with a maximum at $1843 \mathrm{~cm}^{-1}$ due to anhydride groups or a band with a maximum at $1617 \mathrm{~cm}^{-1}$ due to $\mathrm{C}=\mathrm{O}$ stretching, are not visible here. The height of the typical PLA peaks or their ratios do not significantly differ, either. Only a small increase in peak four for all fluid treatments and a slight shift of peak two to smaller wavelengths for IPA, ethanol and heat treatment can be observed.

The chemical analysis thus does not shed light onto the reasons for the mechanical differences between the specimens. This suggests that very small modifications of additional chemicals, or differences in physical properties such as the molecular weight of the samples, leads to significant modifications of their mechanical properties.

\section{Conclusions}

Recovery tests were performed on three different PLA materials, using as-printed as well as post-treated samples. Significant differences between the mechanical properties for the first and subsequent impact and recovery cycles were found, comparing the different materials as well as the various post-treatments. It was clearly shown that a specific post-treatment caused different effects on the different raw materials.

This study shows the importance of careful characterization of each specific material, with or without a possible post-treatment after 3D printing and gives a possible reason for the heterogeneous reports found in different studies on the optimization of printing parameters in terms of mechanical properties of 3D printed objects.

Author Contributions: Conceptualization, G.E. and A.E.; methodology, G.E., B.B. and A.E.; formal analysis, A.E.; investigation, G.E., B.B. and A.E.; writing—original draft preparation, A.E.; writingreview and editing, G.E. and B.B.; visualization, G.E. and A.E. All authors have read and agreed to the published version of the manuscript.

Funding: The study was partly funded by the German Federal Ministry for Economic Affairs and Energy via the AiF, based on a resolution of the German Bundestag, grant number KK5129708TA1.

Data Availability Statement: All data created in this study are shown in this paper.

Conflicts of Interest: The authors declare no conflict of interest. The funders had no role in the design of the study; in the collection, analyses, or interpretation of data; in the writing of the manuscript, or in the decision to publish the results.

\section{References}

1. Blachowicz, T.; Ehrmann, G.; Ehrmann, A. Optical elements from 3D printed polymers. e-Polymers 2021, 21, 549-565. [CrossRef]

2. Duarte, L.C.; Chagas, C.; Ribeiro, L.E.B.; Coltro Tomazelli, W.K. 3D printing of microfluidic devices with embedded sensing electrodes for generating and measuring the size of microdroplets based on contactless conductivity detection. Sens. Actuators $B$ Chem. 2017, 251, 427-432. [CrossRef]

3. Noorani, R. Rapid Prototyping: Principles and Applications; John Wiley \& Sons: New York, NY, USA, 2005.

4. Wan, M.L.; Liu, S.F.; Huang, D.; Qu, Y.; Hu, Y.; Su, Q.S.; Zheng, W.X.; Dong, X.M.; Zhang, H.W.; Wei, Y.; et al. Biocompatible heterogeneous bone incorporated with polymeric biocomposites for human bone repair by 3D printing technology. J. Appl. Polym. Sci. 2020, 138, e50114. [CrossRef]

5. Sölmann, S.; Rattenholl, A.; Blattner, H.; Ehrmann, G.; Gudermann, F.; Lütkemeyer, D.; Ehrmann, A. Mammalian cell adhesion on different 3D printed polymers with varying sterilization methods and acidic treatment. AIMS Bioeng. 2021, 8, 25-35. 
6. Han, S.H.; Cha, M.; Jin, Y.Z.; Lee, K.M.; Lee, J.H. BMP-2 and hMSC dual delivery onto 3D printed PLA-Biogel scaffold for critical-size bone defect regeneration in rabbit tibia. Biomed. Mater. 2021, 16, 015019. [CrossRef] [PubMed]

7. Wickramasinghe, S.; Do, T.; Tran, P. FDM-based 3D printing of polymer and associated composite: A review on mechanical properties, defects and treatments. Polymers 2020, 12, 1529. [CrossRef] [PubMed]

8. Ivanov, E.; Kotsilkova, R.; Xia, H.S.; Chen, Y.H.; Donato, R.K.; Donato, K.; Godoy, A.P.; di Maio, R.; Silvestre, C.; Cimmino, S.; et al. PLA/Graphene/MWCNT composites with improved electrical and thermal properties suitable for FDM 3D printing applications. Appl. Sci. 2019, 9, 1209. [CrossRef]

9. Le Duigou, A.; Chabaud, G.; Matsuzaki, R.; Castro, M. Tailoring the mechanical properties of 3D-printed continuous flax/PLA biocomposites by controlling the slicing parameters. Compos. B Eng. 2020, 203, 108474. [CrossRef]

10. Senatov, F.S.; Zadorozhnyy, M.Y.; Niaza, K.V.; Medvedev, V.V.; Kaloshkin, S.D.; Anisimova, N.Y.; Kiselevskiy, M.V.; Yang, K.-C. Shape memory effect in 3D-printed scaffolds for self-fitting implants. Eur. Polym. J. 2017, 93, 222-231. [CrossRef]

11. Langford, T.; Mohammed, A.; Essa, K.; Elshaer, A.; Hassanin, H. 4D printing of origami structures for minimally invasive surgeries using functional scaffold. Appl. Sci. 2021, 11, 332. [CrossRef]

12. Ehrmann, G.; Ehrmann, A. 3D printing of shape memory properties. J. Appl. Polym. Sci. 2021, 138, 50847. [CrossRef]

13. Wu, W.Z.; Ye, W.L.; Wu, Z.C.; Geng, P.; Wang, Y.L.; Zhao, J. Influence of layer thickness, raster angle, deformation temperature and recovery temperature on the shape-memory effect of 3D-printed polylactic acid samples. Materials 2017, 10, 970. [CrossRef]

14. Senatov, F.S.; Niaza, N.K.; Zadorozhnyy, M.Y.; Maksimkin, A.V.; Kaloshkin, S.D.; Estrin, Y.Z. Mechanical properties and shape memory effect of 3D-printed PLA-based porous scaffolds. J. Mech. Behav. Biomed. Mater. 2016, 57, 139-148. [CrossRef]

15. Lendlein, A.; Langer, R. Biodegradable, elastic shape-memory polymers for potential biomedical applications. Science 2002, 296, 1673-1676. [CrossRef]

16. Ehrmann, G.; Ehrmann, A. Investigation of the shape-memory properties of 3D printed PLA structures with different infills. Polymers 2021, 13, 164. [CrossRef]

17. Ehrmann, G.; Ehrmann, A. Pressure orientation dependent recovery of 3D-printed PLA objects with varying infill degree. Polymers 2021, 13, 1275. [CrossRef] [PubMed]

18. Koske, D.; Ehrmann, A. Infill design for 3D-printed shape memory objects. Technologies 2021, 9, 29. [CrossRef]

19. Srithep, Y.; Nealey, P.; Turng, L. Effects of annealing time and temperature on the crystallinity and heat resistance behavior of injection-molded poly(lactic acid). Polym. Eng. Sci. 2013, 53, 580-588. [CrossRef]

20. Jayanth, N.; Jaswanthraj, K.; Sandeep, S.; Mallaya, N.H.; Siddhartz, S.R. Effect of heat treatment on mechanical properties of 3D printed PLA. J. Mech. Beh. Biomed. Mater. 2021, 123, 104764. [CrossRef]

21. Wang, Y.Q.; Liu, Z.G.; Gu, H.W.; Cui, C.Z.; Hao, J.B. Improved mechanical properties of 3D-printed SiC/PLA composite parts by microwave heating. J. Mater. Res. 2019, 34, 3412-3419. [CrossRef]

22. Lavecchia, F.; Guerra, M.G.; Galantucci, L.M. Chemical vapor treatment to improve surface finish of 3D printed polylactic acid (PLA) parts realized by fused filament fabrication. Prog. Addit. Manuf. 2021. early access. [CrossRef]

23. Valerga, A.P.; Batista, M.; Fernandez-Vidal, S.R.; Gamez, A.J. Impact of chemical post-processing in fused deposition modelling (FDM) on polylactic acid (PLA) surface quality and structure. Polymers 2019, 11, 566. [CrossRef]

24. Panda, S.S.; Chabra, R.; Kapil, S.; Patel, V. Chemical vapour treatment for enhancing the surface finish of PLA object produced by fused deposition method using the Taguchi optimization method. SN Appl. Sci. 2020, 2, 1-13. [CrossRef]

25. Villani, M.; Consonni, R.; Canetti, M.; Bertoglio, F.; Iervese, S.; Bruni, G.; Visai, L.; Iannace, S.; Bertini, F. Polyurethane-based composites: Effects of antibacterial fillers on the physical-mechanical behavior of thermoplastic polyurethanes. Polymers 2020, 12, 362. [CrossRef]

26. Shankar, S.; Rhim, J.-W. Tocopherol-mediated synthesis of silver nanoparticles and preparation of antimicrobial PBAT/silver nanoparticles composite films. LWT-Food Sci. Technol. 2016, 72, 149-156. [CrossRef]

27. Franca, D.C.; Almeida, T.G.; Abels, G.; Canedo, E.L.; Carvalho, L.H.; Wellen, R.M.R.; Haag, K.; Koschek, K. Tailoring PBAT/PLA/Babassu films for suitability of agriculture mulch application. J. Nat. Fibers 2019, 16, 933-943. [CrossRef]

28. Siyamak, S.; Ibrahim, N.A.; Abdolmohammadi, S.; Yunus, W.M.Z.W.; Rahman, M.Z.A.B. Effect of fiber esterification on fundamental properties of oil palm empty fruit bunch fiber/poly(butylene adipate-co-terephthalate) biocomposites. Int. J. Mol. Sci. 2012, 13, 1327-1346. [CrossRef] [PubMed]

29. Zhao, P.; Liu, W.Q.; Wu, Q.S.; Ren, J. Preparation, mechanical, and thermal properties of biodegradable polyesters/poly(lactic acid) blends. J. Nanomater. 2010, 2010, 287082. [CrossRef]

30. Pop, M.A.; Croitoru, C.; Bedo, T.; Geaman, V.; Radomir, I.; Cosnita, M.; Zaharia, S.M.; Chicos, L.A.; Milosan, I. Structural changes during 3D printing of bioderived and synthetic thermoplastic materials. J. Appl. Polym. 2019, 136, 47382. [CrossRef]

31. Garlotta, D. A literature review of poly(lactic acid). J. Polym. Environ. 2001, 9, 63-84. [CrossRef]

32. Jia, W.; Luo, Y.M.; Yu, J.; Liu, B.W.; Hu, M.L.; Chai, L.; Wang, C.Y. Effects of high-repetition-rate femtosecond laser micromachining on the physical and chemical properties of polylactide (PLA). Opt. Express 2015, 23, 26934. [CrossRef] [PubMed]

33. Stepak, B.D.; Antonczak, A.J.; Szustakiewicz, K.; Koziol, P.E.; Abramski, K.M. Degradation of poly(L-lactide) under KrF excimer laser treatment. Polym. Degrad. Stab. 2014, 110, 156-164. [CrossRef] 
34. Shen, W.; Zhang, G.H.; Ge, X.M.; Li, Y.L.; Fan, G.D. Effect of electrospun fibres by synthesis of high branching polylactic acid. R. Soc. Open Sci. 2018, 5, 180134. [CrossRef] [PubMed]

35. Marra, A.; Cimmino, S.; Silvestre, C. Effect of $\mathrm{TiO}_{2}$ and $\mathrm{ZnO}$ on PLA degradation in various media. Adv. Mater. Sci. 2017, 2, 1-8. [CrossRef]

36. Xu, R.J.; Xie, J.Y.; Lei, C.H. Influence of melt-draw ratio on the crystalline behavior of a polylactic acid cast film with a chi structure. RSC Adv. 2017, 7, 39914-39921. [CrossRef] 